
.

\title{
Life-cycle water uses for energy consumption of Chinese households from 2002 to 2015
}

(1) Xiawei Liao ${ }^{1}$, Li Chai ${ }^{2, *}$, Junping Ji ${ }^{3}$, Zhifu Mi ${ }^{4}$, Dabo Guan ${ }^{5}$, Xu Zhao ${ }^{6}$

1, Environmental Change Institute, University of Oxford, Oxford, OX1 3QY, UK 2, International College Beijing, China Agricultural University, Beijing, China

3, School of Environment and Energy, Peking University Shenzhen Graduate School, University Town, Shenzhen 518055, China

4, The Bartlett School of Construction and Project Management, University College London, London WC1E 6BT, United Kingdom

5, Water Security Research Centre, School of International Development, University of East Anglia, Norwich NR4 7TJ, United Kingdom

6, Key Laboratory of Integrated Regulation and Resource Development on Shallow Lakes, Ministry of Education, College of Environment, Hohai University, Nanjing 210098, China

*Corresponding author: Li Chai (Email: chaili2005@163.com; chaili@cau.edu.cn; Phone: +86-010-62737897) 
Abstract: China's household energy demands' life-cycle water uses from 2002 to 2015 are quantified with an Input-Output analysis disaggregating rural and urban impacts. 9.73 and $1.60 \mathrm{~km}^{3}$ of water was withdrawn and consumed respectively in the life cycle of Chinese household energy demands in 2015, which was dominated by power and heat uses. An average urbanite's household energy uses, including coal, gas, petroleum products, power and heat, require about four times of life-cycle water uses than its rural counterpart. Among all upstream sectors, while agricultural sectors accounted for the largest shares for all energy uses, oil and gas extraction made significant contributions to petroleum products and gas consumption. A Structural Decomposition Analysis is conducted to disentangle the impacts of four driving factors, i.e. population, demand, economic structure and technology. Population change reduced energy consumption's life-cycle water use for rural households but increased that for urban households. Each economic sector's water intensity decreases, which represent technology advancement, played the dominant role curbing household energy consumption's life-cycle water uses. While power and heat dominates the household energy use profile, urbanization is accompanied by household consumption shifting from coal to gas and petroleum products. In order to reduce household energy consumption's impacts and reliance on water resources, it is imperative to reduce energy production's water use by adopting water-saving technologies, such as air cooling, as well as to reduce upstream sectors' water intensities, such as by promoting drip irrigation.

Key words: urbanization; household energy consumption; life-cycle water use; 
structural decomposition analysis; input-output model

\section{Introduction}

China has experienced unprecedented economic growth since its "Reform and Opening Up" Policy being initiated in 1978. Such growth has been accompanied by two concurrent changes in terms of its citizens' living conditions: household consumption expansion and rapid urbanization.

China's household consumption has been expanded considerably both as means and results of the substantial economic growth. In 2016, household consumption increase contributed to $64.6 \%$ of China's GDP growth (National Bureau of Statistics, 2016). On one hand, the average household consumption per capita in China has increased by 2.19-fold from 1992 to 2007 (Liu et al., 2011). On the other hand, household consumption composition has undergone significant changes. Food consumption occupies a decreasing share while, on the contrary, numbers of private cars, refrigerators, computers, air conditioners and other energy-consuming appliances have grown considerably, which leads to soaring household energy consumption, e.g. electricity, petroleum products (Liu et al., 2011). China's total household electricity consumption has increased almost three fold from $288.5 \mathrm{TWh}$ in 2005 to 756.5 TWh in 2015. Correspondingly, annual electricity consumption per capita has increased from 220.6 KWh to 550.3 KWh (National Bureau of Statistics, 2016).

Meanwhile, rapid urbanization has taken place in China (Hubacek et al., 2009). In 

2015

\begin{tabular}{lccccccccc}
\hline Per capita & \multicolumn{3}{c}{ Rural Households } & \multicolumn{4}{c}{ Urban Households } \\
\cline { 2 - 6 } $\begin{array}{l}\text { consumption } \\
\text { (RMB per person) }\end{array}$ & 2002 & 2007 & 2012 & 2015 & 2002 & 2007 & 2012 & 2015 \\
Coal & 8.28 & 7.17 & 6.55 & 7.30 & 25.38 & 5.85 & 3.80 & 3.12 \\
Petroleum Products & 5.71 & 7.10 & 13.61 & 21.89 & 20.11 & 60.77 & 129.15 & 167.55 \\
Power and Heat & 24.28 & 49.93 & 57.60 & 74.96 & 167.90 & 214.10 & 177.69 & 189.11 \\
Gas & 0.00 & 3.92 & 5.30 & 8.06 & 30.23 & 27.24 & 87.94 & 127.50 \\
\hline
\end{tabular}


While energy consumption is vital to the wellbeing and functioning of any household in a modern society, it creates environmental externalities throughout its life-cycle supply chain. The most researched and acknowledged environmental impacts from household energy consumption include the emissions of air pollutants and greenhouse gases (Hao et al., 2002; Li et al., 2015; Zhang et al., 2017). It has been concluded that while carbon/pollution intensities declined, population increases, expansion of urbanization and increases in household consumption per capita all contributed to the increase of carbon emissions.

However, the interconnectedness between household energy consumption and its impacts on water resources have been largely overlooked by the existing literature. In order to fulfill final household energy consumption, water is used throughout its life-cycle (Meldrum et al., 2013). Take electricity for example, water is used in the upstream sectors, e.g. coal mining and dressing, as well as in power plants, primarily for cooling purposes (Meldrum et al., 2013). Water footprint has been proposed as an indicator to quantify such impacts (Hoekstra and Chapagain, 2006; Hoekstra et al., 2011). Water footprint includes three components: (1) green water that refers to rainwater stored in soils and vegetation; 2) blue water that is freshwater resources, including surface water and groundwater; 3) grey water that refers to freshwater requirement to dilute pollutants to a permissible concentration by related water quality standards. We are only concerned with surface water use in the blue water category. Moreover, when water is used in the production processes of certain products, it transforms into virtual water and can be transferred with corresponding 
trading activities (Allen, 1993). Based on the Input-Output model first proposed by Leontief (1970), Environmental Extended Input-Output (EEIO) models provide a comprehensive framework as well as a useful tool to assess human activities' impacts on natural resources, e.g. water (Lenzen and Foran, 2001; Lenzen, 2009; Wang et al. 2013). Furthermore, in order to study the impacts of economic, social and technological variables on the various environmental issues, Structural Decomposition Analyses (SDA) within the Input-Output framework has been widely used (Su and Ang, 2012a; Wang et al., 2017; Carrascal-Incera et al. 2017).

Some scholars have quantified the life-cycle water uses for energy production and consumption on various geographical scales (Zhang and Anadon, 2013; Okadera et al. 2015; Wang and Chen, 2016). However, few have shed light on how household consumption, especially with the rapid urbanization and people's change of lifestyles, has impacted this issue. This study aims to quantify the life-cycle water uses to meet China's rural and urban household energy consumption, including coal, petroleum products, gas and power and heat, from 2002 to 2015. These four energy types are studied because they make up the majority of China's household commercial energy consumption that is accounted in the national Input-Output tables (National Academy of Development and Strategy, 2016). Data on non-commercial energy consumption, such as woods, animal excretion, are not available. A structural decomposition analysis (SDA) is conducted to estimate the respective impacts of four driving factors, i.e. population, energy consumption per capita, water intensities and the economic structure, for both rural and urban households. Findings in this study 
126

127

are useful for China, as well as other developing countries that are undergoing rapid urbanization with immense development needs to improve their citizen's rising living standards but also with limited natural resources thus seeking a sustainable development path.

\section{Method and data}

\subsection{Environmental Extended Input Output model}

Input-Output analysis is able to map out the flows of goods and services among the producing and consuming sectors of a given region (Leontief, 1986). By including natural resources as inputs, Environmental Extended Input-Output (EEIO) analysis can be used to track the life-cycle use of natural resources, e.g. water, for the final demands of economic sectors, e.g. energy sectors (Meng et al., 2015; Mi et al., 2016; Mi et al., 2017; Mi et al., 2017). For example, to quantify the life-cycle water use for household energy consumption, the basic equations can be expressed as below:

Where $W_{u}$ and $W_{r}$ are the life-cycle water uses to meet urban and rural household energy consumption $Y_{e, u}$ and $Y_{e, r}$, respectively; $(I-A)^{-1}$ is the Leontief inverse matrix, also called total requirement matrix, that represents the required inputs from each sector to fulfill each sectors' final demands, in which $I$ is an identity matrix and $A$ is 
the matrix of inter-sector intermediate input coefficients; $w^{*}=\left[\mathrm{w}_{1}^{*}, \mathrm{w}_{2}^{*}, \ldots \mathrm{w}_{\mathrm{n}}^{*}\right]$ is a row vector of all sector's water intensities, which equals to direct water inputs in each sector dividing the sector's economic output. In summary, Eq. (1) and (2) calculate how much water inputs to each economic sector's production, $w^{*}$, flow through different economic sectors, $(I-A)^{-1}$, and are used to meet each sector's final demands, e.g. $Y_{e}$ for the energy sector. We do not differentiate imported energy products and domestically produced energy products for household consumption and assume they have the same water intensities.

\subsection{Structural Decomposition Analysis}

According to the Impact $=$ Population $\times$ Affluence $\times$ Technology (IPAT) model $($ Ehrlich and Holdren, 1971; Mi et al., 2017), household energy consumption $Y_{e}$ in Eq. (1) and (2) can be further decomposed to population $P$, including urban and rural, and household energy consumption per capita $y_{e}(\mathrm{MWh} / \mathrm{p})$ as in Eq. (3) and (4).

where water use efficiency of each economic sectors $w^{*}$ denotes the Technology effects; total requirements matrix $(I-A)^{-1}$ represents the Structure Effect; $P$ is the Population Effect and $y_{e}$ is the Demand Effect.

In order to assess those four abovementioned drivers, there are two techniques of 
170

171

172

decomposition, i.e. additive and multiplicative (Su and Ang, 2014, 2015, 2017). We adopt the additive mathematical form as its results are easier to interpret and thus more commonly used in the existing literature (Su and Ang, 2012b). Changes in the life-cycle water uses, $\Delta W$, can be expressed as:

Where $w^{* \prime}, L^{\prime}, P^{\prime}$ and $y_{e}{ }^{\prime}$ denote the impacts brought by changes of water intensities $W^{*}$, Leontief inverse matrix $(I-A)^{-1}$, population $P$ and energy consumption per capita $y_{e}$, respectively.

Assuming during the time interval $[0, t], \Delta W$ can be expressed as Eq. (6):

$\Delta W=W^{t}-W^{0}=w^{* t} L^{t} P^{t} y_{e}{ }^{t}-w^{* 0} L^{0} P^{0} y_{e}{ }^{0}=\left(w^{* 0}+\Delta w^{*}\right)\left(L^{0}+\Delta L\right)\left(P^{0}+\right.$ $\Delta P)\left(y_{e}^{0}+\Delta y_{e}\right)-w^{* 0} L^{0} P^{0} y_{e}^{0}$

Where superscripts all denote either the start, 0 , or the end point, $t$, of the time period $[0, t]$ and $\Delta$ represents the changes of corresponding variables during this time period. S/S method is adopted in this study (Sun, 1998). According to the 'jointly created and equally attributed' principle in Sun (1996), we assume that each factor contributes equally to its joint effects with other factors. For example, $\Delta w^{*}$, $\Delta L, \Delta P$ and $\Delta y_{e}$ all have equal contribution to the mixed term - $\Delta w^{*} \Delta L \Delta P \Delta y_{e}$.

In this way, each term in Eq. (5) can be quantified through breaking down Eq. (6) 
192

193

194

195

196

197

198

mathematically (Details see Appendix). An example equation to quantify $w^{* \prime}$ is as Eq. (7) below:

$w^{* \prime}=\Delta w^{*} L^{0} P^{0} y_{e}{ }^{0}+\frac{1}{2} \Delta w^{*}\left(\Delta L P^{0} y_{e}{ }^{0}+L^{0} \Delta P y_{e}{ }^{0}+L^{0} P^{0} \Delta y_{e}\right)+\frac{1}{3} \Delta w^{*}\left(\Delta L \Delta P y_{e}{ }^{0}+\right.$ $\left.\Delta L P^{0} \Delta y_{e}+L^{0} \Delta P \Delta y_{e}\right)+\frac{1}{4} \Delta w^{*} \Delta L \Delta P \Delta y_{e}$

Similarly, $L^{\prime}, P^{\prime}$ and $y_{e}{ }^{\prime}$ can be quantified. It needs noting that the SDA method we use in this study, S/S method, is a non-chaining method. It means if we are studying changes throughout three time points $a, b$ and $c$, there are two ways to conduct the SDA for the whole period by: (1) analyzing the whole period [a, c] directly or (2) accumulating the results from analyzing $[a, b]$ and $[b, c]$ respectively. The results given by these two ways are not exactly the same. In order to understand the periodical change of the four drivers' impacts, the latter is adopted (Su and Ang 2012b).

\subsection{Data and treatment}

Four time-series Input-Output tables of China's 32 sectors in 2002, 2007, 2012 and 2015 are obtained from the national statistic bureau of China (National Bureau of Statistics, 2016) and all prices are deflated to 2000 prices according to Liu and Peng (2010) (Detailed sector aggregation and deflation method are presented in Supplementary Information). Although there are other international IO databases available, for example, Exiobase (Tukker et al., 2013) and WIOD (Timmer et al., 2015), 
they are more suitable for studying international activities. Moreover, using international databases involves exchanging the currency and induces higher uncertainties in the deflation processes. Therefore China's national statistic data are used. Urban household consumption and rural household consumption are included in the 10 tables. Urban and rural households are classified based on multiple social-economic factors, such as the region's economic structure, population density and so forth. Water use data include both water withdrawal and water consumption. Water initially withdrawn from the environment but not discharged back to any water bodies is defined as water consumption (AQUASTAT, 1998). Water withdrawal data are obtained from the Water Resource Bulletins in these four years (Ministry of Water Resources, 2002, 2007, 2012 and 2015). In the Chinese Water Resources Bulletins, water withdrawal in service sectors is reported together with domestic water withdrawal. About $50 \%$ of the urban domestic water withdrawal was for water use in service sectors. Detailed sectoral distribution of water withdrawals by different industrial and service sectors is approximated by data from the China Economic Census Yearbook 2008 (The State Council Leading Group Office of Second China Economic Census, 2008). Water withdrawal data in each sector are then converted to water consumption by multiplying the water consumption coefficient for that sector, which is taken from Water Resource Bulletins. It needs noting that although hydropower also induces large volumes of water consumption through reservoir evaporation, we do not consider hydropower in this study due to vast methodological disputes and uncertainties (Bakken et al. 2016). 
3. Results

3.1 Life-cycle water uses for household energy consumption in China from 2002 to 2015

240 From 2002 to 2015, the life-cycle water withdrawal for household energy 241 consumption first increased from $10.79 \mathrm{~km}^{3}$ in 2002 to $11.18 \mathrm{~km}^{3}$ in 2007 . It then 242 decreased to $9.08 \mathrm{~km}^{3}$ in 2012 and increased again to $9.73 \mathrm{~km}^{3}$ in 2015 . The life-cycle 243 water consumption has experiences the same changes from $1.16 \mathrm{~km}^{3}$ in 2002 to 1.38 , 1.27 and $1.60 \mathrm{~km}^{3}$ in 2007, 2012 and 2015 respectively. Overall, life-cycle water uses 245 for urban household energy consumption amounted to about 4 times of their rural 246 counterparts.

247 Zhang and Anadon (2013) estimated that 61.4 and $10.8 \mathrm{~km}^{3}$ was withdrawn and 248 consumed, respectively, for the life-cycle of energy production in China in 2007 using 249 a Multi-Regional Input-Output analysis. According to our results, only 11.18 and 1.38 $250 \mathrm{~km}^{3}$ of which was used to meet final household consumption, which indicates that 251 the majority of energy production was used for intermediate inputs to other economic sectors. 


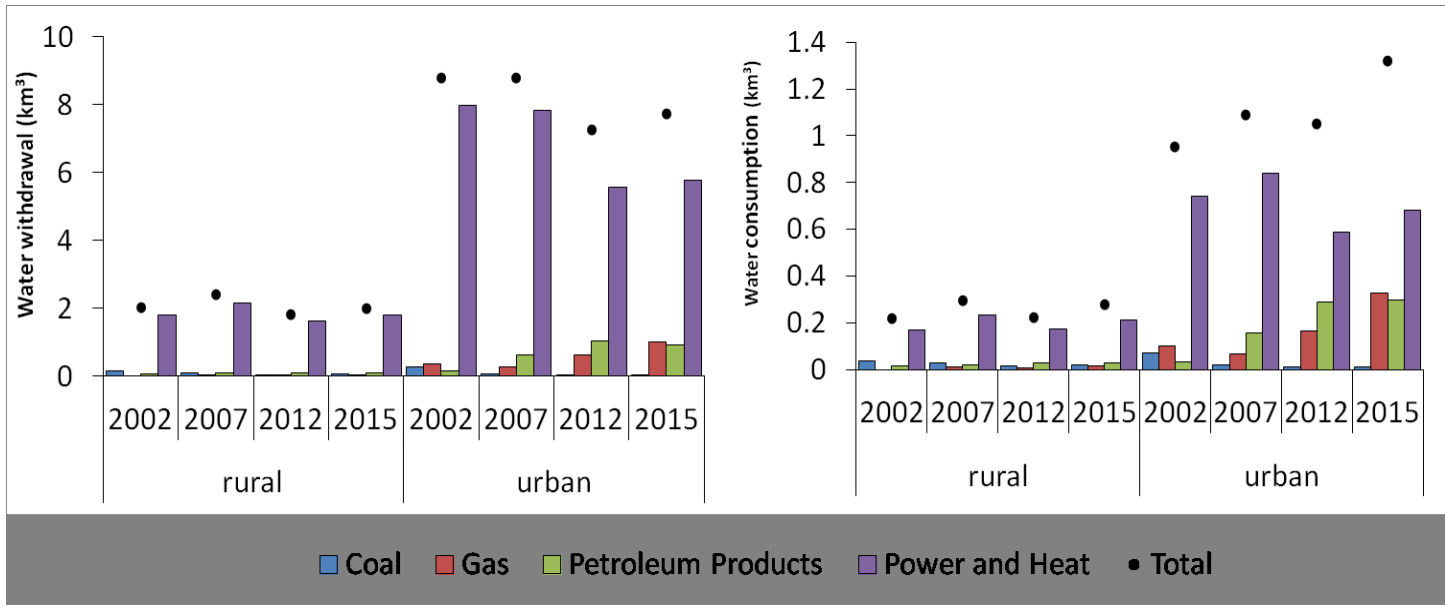

Fig. 1 Life-cycle water uses for households energy consumption from 2002 to 2015

As shown in Fig. 1, life-cycle water uses for household power and heat consumption occupied a dominant but decreasing share, especially for water withdrawal. Life-cycle water withdrawal for household power and heat consumption amounted to $5.66 \mathrm{~km}^{3}$ in 2015 , occupying $74.6 \%$ of the total life-cycle water withdrawal for entire household energy consumption, down from 90.9\%, 89.2\% and 76.7\% in 2002, 2007 and 2012 respectively. Despite the declining share, overall, life-cycle water uses have increased for rural household electricity consumption while decreased for urban household electricity consumption.

Life-cycle water uses for both household gas consumption and petroleum products consumption have increased steadily since 2002. Especially for the life-cycle water consumption, gas consumption and petroleum products have each occupied $24.9 \%$ $\left(0.33 \mathrm{~km}^{3}\right)$ and $22.4 \%\left(0.30 \mathrm{~km}^{3}\right)$ in 2015.

Life-cycle water uses for household coal consumption accounted for the smallest share and have fluctuated throughout the study period. In 2015, only 0.10 and 0.03 
$270 \mathrm{~km}^{3}$ was withdrawn and consumed respectively throughout the entire life-cycle

271 processes to meet household coal consumption in China.

\subsection{Sectoral distribution of household energy consumption's upstream water uses}

Fig. 2 demonstrates the upstream sectoral contributions of energy final demands'

275 life-cycle water uses in 2012. Agricultural, Husbandry, Forestry and Fishing (AHFF)

276 sector and Oil and Natural Gas Extraction (ONGE) sector contributed the biggest

277 shares among all upstream sectors. The main inputs from AHFF to final energy consumption are timbers to produce mine props while Oil and Natural Gas Extraction

279 inputs Crude Oil and Natural Gas to be processed by the Petroleum Refinery and

280 Nuclear Fuel sector and Gas Supply sector, respectively, to provide Petroleum 281 products and Natural Gas for household consumption. 


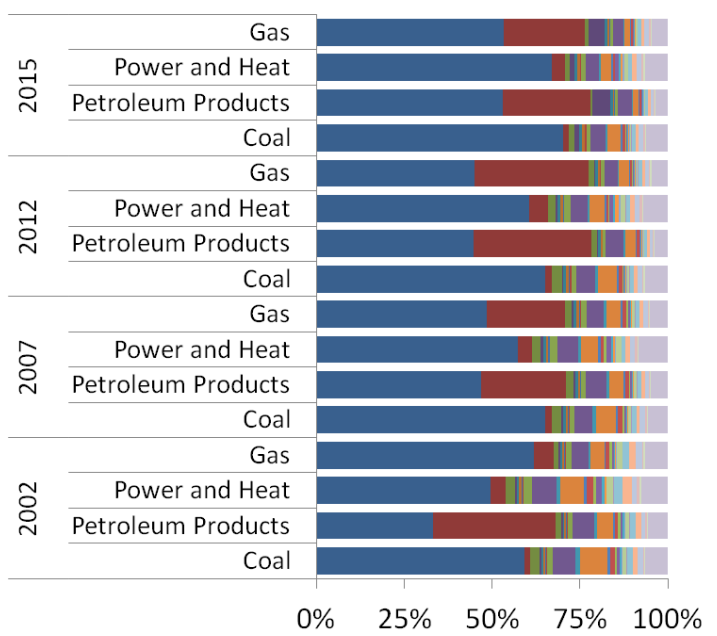

Water withdrawal

Agriculture, husbandry,forestry and fishing
Non-metal ores mining
Wearing apparel and leather products
Chemical products
Metal products
Electric equipment
Other manufactures
Construction
Lodging and catering
Other services

Waste

Other services

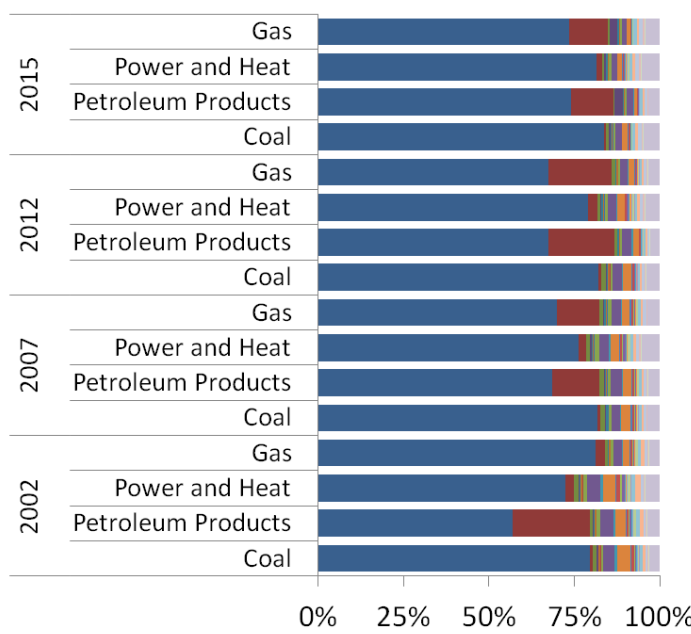

Water consumption

Metal ores mining

Textile

- Paper production and education articles

- Ferrous and nonferrous metals

- Transport equipment

processing and furniture

Nonmetallic mineral products

Communication and electronic equipment

Measuring instruments and office supplies

Finance and insurance $\quad$ Real estate

Fig. 2 Sectoral distribution of household energy consumption's upstream life-cycle

water uses

AHFF is the biggest contributor to the upstream water uses by the consumption of all

288 four types of energy sources. Particularly for coal consumption, AHFF made up $70.0 \%$

of its upstream water withdrawal and $83.5 \%$ of its upstream water consumption in 
regulations that can be thoroughly implemented is also crucial.

297

\subsection{Driving factors of household energy consumption's life-cycle water use changes}

299 The impacts of four driving factors are analyzed for the changes of life-cycle water 300 uses of each energy type's final consumption. It can be seen from Fig. 3 that from 2002 to 2015 , population change has had consistent negative effects on the life-cycle water uses ( $0.57 \mathrm{~km}^{3}$ of water withdrawal and $0.07 \mathrm{~km}^{3}$ of water consumption) of 303 rural households' consumption of all energy sources while positive effects on those 304 of urban households $\left(3.70 \mathrm{~km}^{3}\right.$ of water withdrawal and $0.47 \mathrm{~km}^{3}$ of water 305 consumption), which is in line with the continuing declining rural population and increasing urban population. 

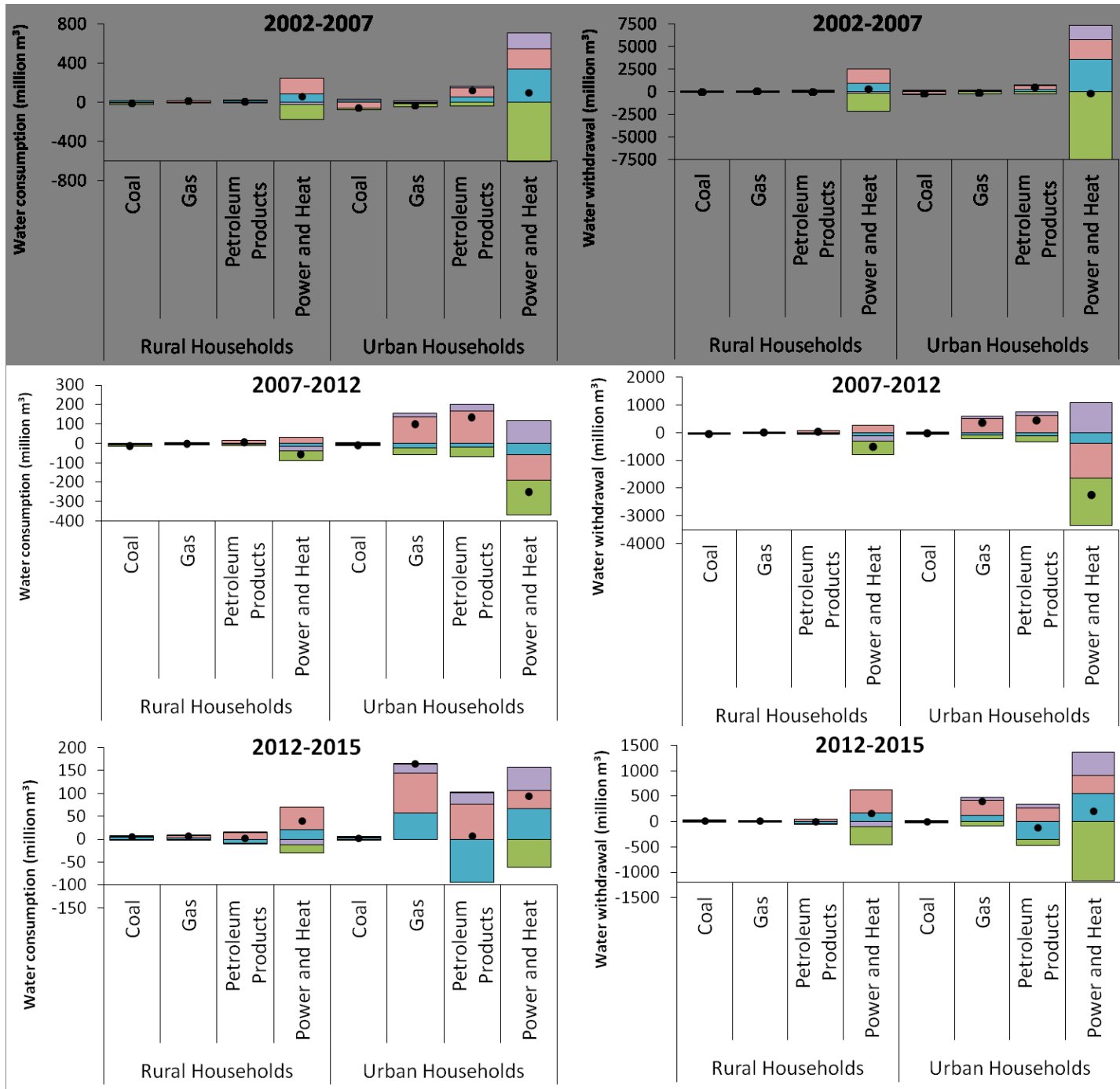

$\square$ Technology Effect $\square$ Population Effect $\square$ Demand Effect $\square$ Structural Effect • Total Change

Fig. 3 Drivers of household energy consumption's life-cycle water use changes

From 2002 to 2015, per capita coal consumption for urban households has kept decreasing and leads to 0.27 and $0.07 \mathrm{~km}^{3}$ of water withdrawal and consumption

313 reductions. Such effects were especially acute from 2002 to 2007, occupying just

314 below $90 \%$ of the total reductions. On the contrary, per capita demands for petroleum products have gone up consistently throughout the study period and resulted in 0.13 and $0.03 \mathrm{~km}^{3}$ of water withdrawal and consumption increases, 
respectively, for rural households and 1.28 and $0.26 \mathrm{~km}^{3}$ for urban households. These increases reflected the soaring vehicle ownerships in China and people's growing demands for higher mobility.

Despite the increase from 2002 to 2007, urban households' per capita power and heat demand has decreased from 2007 to 2012, resulting in 1.25 and $0.13 \mathrm{~km}^{3}$ of water withdrawal and consumption declines, respectively. Such demand decreases could be resulted from the aftermath of global financial crisis and economic stalemate, which has also been found affecting China's carbon emission change (Mi et al. 2017).

Economic structure change has contributed to 5.04 and $0.52 \mathrm{~km}^{3}$ of water withdrawal and consumption increases, respectively, from 2002 to 2007 . The effects reversed from 2007 offsetting 0.74 and $0.13 \mathrm{~km}^{3}$ of water withdrawal and consumption increases, respectively. However, from 2012 onwards, economic structure change has had positive effects since. The structure change of the economy's intermediate production inputs has shifted from a major driving factor for household energy consumption's water uses to an offsetting one from 2007 and changed back to a driving factor from 2012. Reducing the inputs from upstream water-intensive sectors to the energy sector can help utilizing the offsetting potential of the structural effect to reduce final energy demands impacts and dependencies on water resources.

Overall, technology advancement played the essential role consistently reducing household energy consumption's life-cycle water uses, offsetting 14.46 and $1.29 \mathrm{~km}^{3}$ 
of water withdrawal and consumption, respectively, in total from 2002 to 2015 . This indicates that water efficiency improvement in other sectors has generated co-benefits of reducing household energy consumption's reliance on water. Further actions to continue improving water efficiency in the upstream sectors are thus imperative. Taking the agriculture industry for example, in order to improve the water efficiency for irrigation, drip irrigation and alternative crops should be promoted (Levidow et al. 2014).

\section{Discussions}

\subsection{Promote sustainable urbanization and consumer behaviors}

China has lifted over 800 million people out of poverty and the improvement of people's living standards has been accompanied by growing energy consumption. However, such growth has imposed increasing pressures on the natural environment, such as water resources. Environmentally responsible and sustainable consumption behaviours should be encouraged, especially among the increasing number of urbanites, who consume significant larger amount of energy than their rural counterparts.

Various policy instruments can be utilized. Market mechanisms such as subsidies for energy-efficient household appliances, e.g. air conditioner, fridge, can be effective. Environmental education to raise environmental awareness as well as environmental information disclosure programs, such as energy labelling, should be adopted. Public transportation should be further enhanced to reduce private car ownership as well 
as the corresponding oil consumption.

362

\subsection{Reduce energy production's direct water uses}

A large amount of water is used in energy productions. Zhang and Anadon (2013) have pointed out that electricity production dominates such water uses. As many of

China's thermoelectric power plants are located in water-stressed areas that are close to coal reserves, it is important to encourage more efficient use of water in those power plants. Improving their energy conversion efficiency and changing cooling technologies are both feasible options. For example, since 2004, new power plants are required to employ air cooling systems with water withdrawal intensities

371 less than $0.18 \mathrm{~m}^{3} \mathrm{~s}^{-1} \mathrm{GW}$ in water-stressed regions (National Development and Reform Commission 2004).

373 Furthermore, although grey water use is not considered in this study, energy 374 production and consumption also induce serious water pollution issues, especially 375 during coal mining processes. Enforcing wastewater treatment at coal mines is necessary.

\subsection{Concerted effort is required to reduce energy consumption's indirect water uses}

379 Energy consumption's life-cycle water uses also depend on its upstream sectors, 380 therefore concerted efforts to save water are required throughout the entire 381 economy. For example, while household gas consumption has been steadily 382 increasing and China's Sichuan province is endowed with rich shale gas resources. 
383

384

Water uses in the extraction processes, such as hydraulic fracturing, should be further studied in the regional context before any exploitation plan is made. Gas liquefaction is another industry that needs to be developed with caution. Water scarcities have forced China to ban several Gas-to-Liquid factories in water-stress regions (Qin et al. 2015).

\subsection{Limitations and future research directions}

Although household energy consumption magnitudes and patterns differ by region, for example, northern households use more energy for heating during winters, spatial disaggregation remains a limitation of this study. This study is the first study disaggregating rural and urban households and looking at urbanization's impact on China's water-for-energy uses. Future study with higher spatial resolution using China's Multi-Regional Input-Output tables can be conducted.

Furthermore, while the additive form of SDA is used in this study to assess the drivers of absolute water uses for household energy consumption, studies using the multiplicative form to quantify the water intensity changes and corresponding drivers will also be valuable (Su and Ang, 2015; Carrascal Incera et al. 2017).

Last but not least, while this study uses urban and rural household consumption data from the national Input-Output tables, future studies are encouraged to quantify the impacts of changes in household demographical characteristics, e.g. ages, income, and consumer behaviours, e.g. car ownership, house type, on resources use based on national household budget surveys. 
Acknowledgements:

407 This work is supported by China Scholarship Council - Oxford University Scholarship, 408 National Natural Science Foundation of China (51639009) and the National Key R\&D Program of China (2017YFC0403301).

\section{References:}

Allan, J.A., 1993. "Fortunately, There Are Substitutes for Water Otherwise Our Hydro-political Futures Would be Impossible. Priorities for water resources allocation and management." in: Overseas Development Administration (Ed.), London, pp. 13-26.

AQUASTAT. 1998. "AQUASTAT definitions." FAO, Rome, Italy.

Bakken, T.H., Modahl, I.S., Raadal, H.L., Bustos, A.A. and Arnoy S. 2016 “Allocation of water consumption in multipurpose reservoirs." Water Policy 1-17.

Carrascal-Incera, A., Avelino, A. F., \& Solís, A. F. 2017. “Gray water and environmental externalities: International patterns of water pollution through a structural decomposition analysis." Journal of Cleaner Production, 165, 1174-1187.

Central Committee of the Communist Party of China and State Council. 2014. “National New Urbanization Plan (2014-2020).” Beijing, China.

Ehrlich, P.R. and Holdren, J.P. 1971. "Impact of population growth." Science 171: $1212-1217$.

Hao, J M, H Z Tian, and Y Q Lu. 2002. “Emission Inventories of NOx from Commercial 

Energy Consumption in China, 1995-1998." Environmental Science \& Technology 36 (4): 552-60. https://doi.org/10.1021/es015601k.

Hoekstra, A. Y., and Chapagain, A. K. 2006. "Water footprints of nations: water use by people as a function of their consumption pattern." in: Integrated assessment of water resources and global change (pp. 35-48). Springer, Dordrecht.

Hoekstra, A.Y., Chapagain, A.K., Aldaya, M.M. and Mekonnen, M.M. 2011. "The Water Footprint Assessment Manual: Setting the Global Standard." London: Earthscan, 1-209.

Hubacek, Klaus, Guan, D., Barrett, J. and Wiedmann, T. 2009. "Environmental Implications of Urbanization and Lifestyle Change in China: Ecological and Water Footprints." Journal of Cleaner Production 17(4): 1241-1248.

Leontief, W. 1970. "Environmental repercussions and the economic structure: an input-output approach." The Review of Economics and Statistics 52(3): 262-271.

Leontief, W. 1986. "Input-Output Economics." Oxford University Press, Oxford, UK.

Lenzen, M. and Foran, B. 2001. "An input-output analysis of Australian water usage." Water Policy 3(4): 321-340.

Lenzen, M. 2009. "Understanding virtual water flows: a multi-regional input-output case study of Victoria." Water Resources Research 45(9): WR007649.

Levidow, L., Zaccaria, D., Maia, R., Vivas, E., Todorovic, M. and Scardigno, A. 2014. "Imporving water-efficient irrigation: prospects and difficulties of innovative practices." Agricultural Water Mangement 146: 84-94.

Li, Y.M., Zhao, R, Liu, T. and Zhao, J.F. 2015. “Does Urbanization Lead to More Direct 
and Indirect Household Carbon Dioxide Emissions? Evidence from China during 1996-2012." Journal of Cleaner Production 102: 103-114.

Liu, L.C., Wu, G., Wang, J.N. and Wei, Y.M. 2011. “China's Carbon Emissions from Urban and Rural Households during 1992-2007." Journal of Cleaner Production 19(15): 1754-1762.

Liu, Q. and Peng, Z. 2010. "Comparable price input-output tables and analyses in China 1992-2005 (中国1992-2005年可比价投入产出序列表及分析)." China Statistics Press, Beijing, China.

Meldrum, J., S. Nettles-Anderson, G. Heath, and J. Macknick. 2013. “Life-cycle Water Use for Electricity Generation: A Review and Harmonization of Literature Estimates." Environmental Research Letters 8: 15031.

Meng, J., Liu, J., Xu, Y. and Tao, S. 2015. "Tracing Primary PM2.5 Emissions via Chinese Supply Chains." Environmental Research Letters 10: 54005.

Ministry of Water Resources. 2012. "Chinese Water Resources Bulletin 2012." China Water\&Power Press, Beijing, China.

Ministry of Water Resources. 2007. "Chinese Water Resources Bulletin 2007." China Water\&Power Press, Beijing, China.

Ministry of Water Resources. 2002. "Chinese Water Resources Bulletin 2002." China Water\&Power Press, Beijing, China.

Mi, Z.F., Meng, J., Guan, D.B., Shan, Y.L., Song, M.L., Wei, Y.M., Liu, Z. and Hubacek, K. 2017. "Chinese CO2 emission flows have reversed since the global financial crisis." Nature Communications 8, 1712. 
471

472

473

Mi, Z.F., Zhang, Y.K., Guan, D.B., Shan, Y.L., Liu, Z., Cong, R.G., Yuan, X.C. and Wei, Y.M. 2016. "Consumption-based emission accounting for Chinese cities." Applied Energy 184:1073-1081.

Mi, Z.F., Meng, J., Guan, D.B., Shan, Y.L., Liu, Z., Wang, Y.T., Feng, K.S. and Wei, Y.M. 2017. "Pattern Changes in Determinants of Chinese Emissions." Environmental Research Letters 12 (7). https://doi.org/10.1088/1748-9326/aa69cf.

National Academy of Development and Strategy. 2016. " Chinese Household Energy Consumption in 2015." Renmin University of China. Beijing, China.

National Bureau of Statistics of China. 2016. "Chinese Energy Statistics Yearbook." China Statistics Press, Beijing, P.R.C. (in Chinese).

National Bureau of Statistics of China. 2016. "Chinese Statistics Yearbook." China Statistics Press, Beijing, P.R.C. (in Chinese).

National Bureau of Statistics. 2016. "National Input-Output Tables, 2002, 2007 and 2012." Beijing, China.

National Development and Reform Commission. 2004. "Requirements on the Planning and Construction of Coal Power Plants." Beijing, China.

Okadera, T., Geng, Y., Fujita, T., Dong, H., Liu, Z. and Yoshida, N. 2015. "Evaluating the water footprint of the energy supply of Liaoning Province, China: a regional input-output analysis approach." Energy Policy 78: 148-157.

Qin, Y., Curmi, E., Kopec, G.M., Allwood, J.M. and Richards, K.S. 2015. "China's energy-water nexus - assessment of the energy sector's compliance with the "3 Red Lines" industrial water policy." Energy Policy 82: 131-143. 
493

494

495

496

497

498

499

500

501

502

503

504

505

506

507

508

509

510

Su, B. and Ang, B.W. 2012a. "Structural decomposition analysis applied to energy and emissions: some methodological developments." Energy Economics 34(1): 177-188.

Su, B. and Ang, B.W. 2012b. "Structural decomposition analysis applied to energy and emissions: aggregation issues." Economic Systems Research, 24(3), 299-317.

Su, B. and Ang, B.W. 2014. "Attribution of changes in the generalized Fisher index with application to embodied emission studies." Energy 69: 778-786.

Su, B. and Ang, B.W. 2015. "Multiplicative decomposition of aggregate carbon intensity change using input-output analysis." Applied Energy 154: 13-20.

Su, B. and Ang, B.W. 2017. "Multiplicative structural decomposition analysis of aggregated embodied energy and emission intensities." Energy Economics 65: 137-147.

Sun, J.W. 1996. "Quantitative analysis of energy consumption, efficiency and savings in the world, 1973 - 1990." Turku School of Economics Press. Turku, Finland.

Sun, J.W. 1998. "Changes in Energy Consumption and Energy Intensity: A Complete Decomposition Model." Energy Economics 20(1): 85-100.

Timmer, M.P., Dietzenbacher, E., Los, B., Stehrer, R., and De Vries, G.J. 2015. "An illustrated user guide to the world input-output database: the case of global automotive production." Review of International Economics 23(3), 575-605.

The State Council Leading Group Office of Second China Economic Census. 2008. "China Economic Census Yearbook 2008." Beijing, China.

Tukker, A., de Koning, A., Wood, R., Hawkins, T., Lutter, S., Acosta, J., ... \& Kuenen, J. 
2013. "EXIOPOL-development and illustrative analyses of a detailed global MR EE SUT/IOT." Economic Systems Research, 25(1), 50-70.

Wang, H., Ang, B.W. and Su, B. 2017. "Assessing drivers of economy-wide energy use and emissions: IDA versus SDA." Energy Policy 107: 585-599.

Wang, S. and Chen, B. 2016. "Energy-water nexus of urban agglomeration based on

Zhang, C.G. and Lin, Y. 2012. "Panel Estimation for Urbanization, Energy Consumption and CO 2 Emissions: A Regional Analysis in China." Energy Policy 49: 488-498.

Zhang, Y.J., Bian, X.J., Tan, W.P. and Song, J. 2017. “The Indirect Energy Consumption 533 